\title{
AVALIAÇÃO DA QUALIDADE DA ÁGUA DE BACIAS HIDROGRÁFICAS ATRAVÉS DA FERRAMENTA DO ÍNDICE DE QUALIDADE DA ÁGUA - IQA
}

\author{
Lucivania Pereira Gloria ${ }^{1}$, Bruna Carolina Horn ${ }^{2}$, Maurício Hilgemann ${ }^{3}$
}

\begin{abstract}
Resumo: Durante séculos a água foi considerada um bem de domínio público e de quantidade infinita. Atualmente, a preocupação mundial está voltada para a qualidade da água para consumo humano, uma vez que o desenvolvimento das cidades e o aumento populacional acabaram influenciando diretamente no aumento da poluição e degradação dos recursos naturais. Consequentemente, faz-se necessário o uso de mecanismos que viabilizem os padrões dos corpos d'água e a determinação de sua qualidade. Diversas ferramentas foram propostas com base em características físicas, químicas e bacteriológicas da água. Destas, destaca-se o Índice de Qualidade da Água (IQA), que é uma importante metodologia para mensurar o padrão das águas nacionais. Assim, este artigo apresenta a problemática da qualidade da água de bacias hidrográficas brasileiras e estudos realizados para a avaliação da qualidade da água utilizando o IQA.
\end{abstract}

Palavras-chave: Água. Qualidade. Bacias hidrográficas.

\section{EVALUATION OF WATER QUALITY OF HYDROGRAPHIC BASINS THROUGH THE WATER QUALITY INDEX TOOL - WQI}

Abstract: For centuries water was considered a public domain property of infinite quantity. Currently, the world's concern is focused on the quality of water for human consumption, since the development of cities and the increase in population have directly influenced the increase of pollution and degradation of natural resources. Consequently, it is necessary to use mechanisms that enable the standards of water bodies and the determination of their quality. Several tools were proposed based on the physical, chemical and bacteriological characteristics of the water. Among them, the Water Quality Index (WQI) stands out, which is an important methodology to measure the national water standard. Thus, this article presents

1 Graduada em Tecnologia em Logística. Mestranda do Programa de Pós-Graduação em Ambiente e Desenvolvimento (PPGAD) do Centro Universitário UNIVATES. E-mail: lucivania.gloria@ifto.edu.br

2 Graduanda em Engenharia Ambiental do Centro Universitário UNIVATES. E-mail: bruna.horn@univates.br

3 Doutor em Química Analítica. Professor do Programa de Pós-Graduação em Ambiente e Desenvolvimento (PPGAD) e do Centro de Ciências Exatas e Tecnológicas do Centro Universitário UNIVATES. E-mail: mauricio.hilgemann@univates.br 
the water quality problem of Brazilian basins and studies carried out to evaluate the water quality using the WQI.

Keywords: Water. Quality. Hydrographic basins.

\section{INTRODUÇÃO}

Durante séculos a água foi considerada um bem de domínio público e de quantidade infinita. Sua disponibilidade sempre esteve à disposição do homem por ser um recurso natural autossustentável possuindo a capacidade de restaurar suas características ambientais naturalmente. Atualmente, a preocupação mundial está voltada para a qualidade da água para consumo humano, uma vez que o desenvolvimento das cidades e o aumento populacional acabaram influenciando diretamente no aumento da poluição e degradação dos recursos naturais (JUNIOR, 2005). As influências antrópicas sobre a qualidade da água estão fortemente associadas ao crescimento da urbanização, da expansão das atividades agropecuárias e industriais. Deste modo, há a necessidade de enquadramento dos recursos hídricos aos diferentes níveis de qualidade, já que se designam a usos múltiplos (SÁ; CAMPOS, 2003).

Contudo, faz-se necessário o uso de mecanismos que viabilizem os padrões dos corpos d'água e a determinação de sua qualidade. Diversas ferramentas foram propostas com base em características físicas, químicas e bacteriológicas da água, cabendo ajustes nos pesos e parâmetros para adequação à realidade regional. Destas, destaca-se o Índice de Qualidade da Água (IQA), que é uma importante metodologia para mensurar o padrão das águas nacionais (AGÊNCIA NACIONAL DE ÁGUAS, 2017).

O acompanhamento e monitoramento da qualidade de um recurso hídrico, através de amostragem conforme suas características busca obter informações qualitativas e quantitativas, atingindo propósitos específicos, como o conhecimento das condições biológicas, químicas, físicas e ecológicas, e enquadramentos em classes ou para efeitos de fiscalização (AGÊNCIA NACIONAL DE ÁGUAS, 2017). No Brasil, a categorização dos corpos d'água foi definida pela resolução 357 de 2005, do Conselho Nacional de Meio Ambiente (CONAMA), onde são estabelecidas as diretrizes para a classificação dos corpos hídricos em classes de uso, bem como os padrões de qualidade e para o lançamento de efluentes (BRASIL, 2005). As informações sobre a qualidade da água são fundamentais para que se conheça a situação em relação aos seus usos múltiplos e impactos ambientais $\mathrm{O}$ crescimento demográfico e o desenvolvimento socioeconômico estão sempre acompanhados pela necessidade de água, cuja qualidade e quantidade são de grande importância para a saúde e desenvolvimento de qualquer grupo (BUENO et al., 2005).

Considerando o exposto, este artigo apresenta a problemática da qualidade da água de bacias hidrográficas brasileiras, as políticas nacionais de recursos hídricos e gestão das bacias hidrográficas, bem como o monitoramento dos principais parâmetros 
para avaliação da sua qualidade. Ainda, apresenta o IQA e estudos realizados para a avaliação da qualidade da água de bacias hidrográficas brasileiras.

\section{QUALIDADE DA ÁGUA}

O termo "qualidade de água" não trata apenas o estado de pureza da mesma, mas sim às características físicas, químicas e biológicas e, dependendo destas características, são determinados diversos destinos para a água. A qualidade da água de um determinado recurso hídrico é avaliada dependendo das substâncias presentes na água, para isso denominada de parâmetros de qualidade da água. Tais substâncias caracterizam as condições em que a água se encontra, para os mais variados usos, inclusive para sua preservação no ambiente (MERTEN, MINELLA, 2002). As condições geológicas, geomorfológicas e da vegetação na bacia de drenagem, o desempenho dos ecossistemas terrestres e aquáticos e da ação humana, podem alterar a qualidade da água. As ações antropogênicas são as que possuem maior impacto devido aos lançamentos de cargas poluentes nos sistemas hídricos e a alteração do uso da terra acaba provocando intervenções diretas no sistema fluvial (TUCCI, 2007).

Os usos múltiplos dos recursos hídricos nas bacias hidrográficas acarretam grandes variações das características físicas, químicas e bacteriológicas ao longo de seu percurso. Estas características ou parâmetros quando avaliados em conjunto, possibilitam verificar os níveis de poluição de um determinado manancial, promovendo a definição da qualidade da água e seu enquadramento dentro de classes (CARVALHO, 2005).

\subsection{Degradação ambiental e fontes de poluição}

A legislação que conceitua a degradação ambiental no Brasil é a lei n 6.938, de 31 de agosto de 1981, que dispõe a Política Nacional do Meio Ambiente, que versa sobre "a alteração adversa das características do meio ambiente" (BRASIL,1981).

Com a crescente degradação nas bacias hidrográficas, os ecossistemas aquáticos acabam servindo de depósitos de uma grande diversidade e quantidade de poluentes lançados pelo homem, sejam eles pelo ar, solo ou diretamente nas bacias. Assim, a poluição do ambiente aquático, provocada pelo homem, direta ou indiretamente, produz efeitos deletérios tais como: prejuízos aos seres vivos, perigo à saúde humana, efeitos negativos às atividades aquáticas (pesca, lazer etc) e prejuízo à qualidade de água com respeito ao uso na agricultura, indústria e outras atividades econômicas (MEYBECK; HELMER, 1996).

Von Sperling (2005) classifica as fontes de poluição em pontual e difusa. Para ele, a poluição pontual acontece quando os poluentes atingem o corpo d'água de forma concentrada; a poluição difusa ocorre quando os poluentes adentram o corpo d'água distribuído ao longo de sua extensão. A fonte de poluição pontual pode ser reduzida 
ou eliminada através de tratamento apropriado para posterior lançamento em um corpo receptor, embora muitas vezes estes resíduos sem tratamento sejam lançados diretamente nos corpos de água, causando sérios impactos as biotas, aos recursos hídricos, ao homem e aos demais componentes do sistema (BRITO, 2005). As fontes difusas caracterizam-se por apresentarem múltiplos pontos de descarga resultantes do escoamento em áreas urbanas e/ou agrícolas e ocorrem durante os períodos de chuva, atingindo concentrações bastante elevadas dos poluentes. A redução dessas fontes geralmente requer mudanças nas práticas de uso da terra e na melhoria de programas de educação ambiental (MEYBECK, 2004).

\section{POLÍTICA NACIONAL DE RECURSOS HÍDRICOS}

No dia 08 de janeiro de 1997 foi instituído, pela lei n 9.433, a Política Nacional de Recursos Hídricos que criou o Sistema Nacional de Gerenciamento de Recursos Hídricos (BRASIL, 1997). Segundo esta lei, a água é um recurso natural limitado de valor econômico e bem de domínio público. Quando esse bem se apresenta em situação de escassez, seu uso se torna prioritário para o consumo humano e a dessedentação de animais, cabendo à gestão dos recursos hídricos proporcionar o uso múltiplo das águas. A lei menciona ainda a bacia hidrográfica como a unidade territorial para implementação da Política Nacional de Recursos Hídricos e atuação do Sistema Nacional de Gerenciamento de Recursos Hídricos, sendo que a gestão dos recursos hídricos deve ser descentralizada e contar com a participação do Poder Público, dos usuários e das comunidades (BRASIL, 1997).

Os objetivos da Política Nacional de Recursos Hídricos são: assegurar à atual e às futuras gerações a necessária disponibilidade de água, em padrões de qualidade adequados aos respectivos usos; a utilização racional e integrada dos recursos hídricos, incluindo o transporte aquaviário, com vistas ao desenvolvimento sustentável; prevenção e defesa contra eventos hidrológicos críticos de origem natural ou decorrentes do uso inadequado dos recursos naturais (BRASIL, 1997).

Os Planos de Recursos Hídricos são planos diretores que visam fundamentar e orientar a implementação da Política Nacional de Recursos Hídricos e o gerenciamento dos recursos hídricos. Outros cinco aspectos relevantes da Política Nacional de Recursos Hídricos são: o enquadramento dos corpos de água em classes segundo os usos preponderantes da água; a outorga dos direitos de uso de recursos hídricos; a cobrança pelo uso de recursos hídricos; a compensação a municípios; e o Sistema de Informações sobre Recursos Hídricos (BRASIL, 1997).

No Brasil, o órgão responsável pela classificação dos corpos d'água e diretrizes ambientais para o seu enquadramento, bem como estabelecer as condições e padrões de lançamentos de efluentes, é o CONAMA, ligado ao Ministério do Meio Ambiente. A Resolução desse Conselho sobre Recursos Hídricos é a de no 357, de 17 de março de 2005 (BRASIL, 2005). Nesse documento, as águas doces são classificadas em 
cinco classes: especial, 1, 2, 3 e 4. Dessas, somente a classe 4 não pode ser utilizada no abastecimento ou qualquer outro tipo de utilização humana nem com a maioria dos seres vivos, devido à sua baixa qualidade, cujos custos de tratamento inviabilizam o seu aproveitamento. As demais diferem entre si pelo tipo de tratamento a ser utilizado na desinfecção das mesmas, antes de sua distribuição à população (BRASIL, 2005).

\section{GESTÃO DAS BACIAS HIDROGRÁFICAS}

Uma bacia hidrográfica é definida como uma área de captação natural de água precipitada que faz convergir os escoamentos para um único ponto de saída. Pode ser considerada como um sistema físico onde a entrada de água é produto da precipitação e a saída é o volume de água escoada superficialmente, levando-se em consideração as diversas perdas intermediárias como evaporação, transpiração e as perdas por percolação profunda (TUCCI, 2007).

A bacia hidrográfica é o espaço físico de gestão dos diversos usos da água, onde se pode melhor perceber e entender os impactos sobre a quantidade e principalmente a qualidade da água como resultante de fenômenos naturais e da atuação do homem. De maneira geral, pode-se dizer que a qualidade de uma determinada água é função das condições naturais e do uso e ocupação da terra na bacia hidrográfica (VON SPERLING, 2005). Assim, a gestão destes recursos hídricos deve ser descentralizada e contar com a participação do poder público, dos usuários e das comunidades, por intermédio dos Comitês de Bacias Hidrográficas (MOTA, 2012).

Os Comitês de Bacia Hidrográfica são organismos colegiados que fazem parte do Sistema Nacional de Gerenciamento de Recursos Hídricos e existem no Brasil desde 1988. A composição diversificada e democrática dos Comitês contribui para que todos os setores da sociedade com interesse sobre a água na bacia tenham representação e poder de decisão sobre sua gestão $(\mathrm{CBH}, 2017)$. Dentre as atribuições destes Comitês, cabe, por exemplo, promover o debate das questões relacionadas a recursos hídricos e articular a atuação das entidades intervenientes; arbitrar, em primeira instância administrativa, os conflitos relacionados aos recursos hídricos; aprovar o Plano de Recursos Hídricos da bacia; acompanhar a execução do Plano de Recursos Hídricos da bacia e sugerir as providências necessárias ao cumprimento de suas metas; estabelecer os mecanismos de cobrança pelo uso de recursos hídricos e sugerir os valores a serem cobrados; e estabelecer critérios e promover o rateio de custo das obras de uso múltiplo, de interesse comum ou coletivo (BRASIL,1997).

\section{MONITORAMENTO DAÁGUA}

O monitoramento da qualidade da água prevê o levantamento sistemático de dados em pontos de amostragem previamente selecionados, com muitas observações, medições e avaliações para obter informações ou comportamentos de um conjunto 
de variáveis, acompanhando as condições de qualidade de água ao longo do tempo (DERISIO, 1992). O monitoramento qualitativo e quantitativo dos recursos hídricos se constitui num poderoso instrumento, que possibilita a avaliação da oferta hídrica, que é a base para decisões do aproveitamento múltiplo e integrado da água, bem como para a minimização de impactos ao meio ambiente (COIMBRA, 1991).

O monitoramento da qualidade das águas superficiais são fatores primordiais para a adequada gestão dos recursos hídricos, permitindo a caracterização e a análise de tendências em bacias hidrográficas, sendo essenciais para várias atividades de gestão, tais como: planejamento, outorga, cobrança e enquadramento dos cursos de água (AGÊNCIA NACIONAL DE ÁGUAS, 2017). O monitoramento também é efetivo para indicar mudanças na qualidade da água em função do uso e ocupação do solo. Assim, parcerias com órgãos de fiscalização podem ser muito eficazes no sentido de detectar mudanças de qualidade ambiental, facilitando a tomada das devidas providências técnicas e legais pelos órgãos competentes, contribuindo para preservação e recuperação dos ecossistemas. O monitoramento da qualidade da água é fundamental para otimização da gestão hídrica por fornecer informações sobre suas formas de uso nas bacias hidrográficas (TEIXEIRA, 2000). Os diversos componentes presentes na água, que alteram suas características naturais, podem ser retratados em termos de concentrações e variações de parâmetros físicos, químicos e biológicos.

\section{6 ÍNDICE DE QUALIDADE DE ÁGUA (IQA)}

Para facilitar a divulgação e interpretação de dados sobre os parâmetros de qualidade das águas ao público leigo, tem-se adotado os Índices de Qualidade das Âguas que expressam, através de um valor único, a qualidade das águas em um ponto de monitoramento específico, o qual aponta de forma classificatória a qualidade da água (VON SPERLING, 2005, BRAGA et al., 2005).

Diversos índices de qualidade foram desenvolvidos por diferentes entidades e com propósitos distintos, sendo que todos eles possuem em comum a combinação ponderada de um conjunto de fatores (BRAGA et al., 2005). Porém, o índice mais conhecido e utilizado por pesquisadores é o índice desenvolvido pela National Sanitation Foundation (NSF) que, a partir da década de 1970, passou a ser utilizado pela CETESB em São Paulo (AGÊNCIA NACIONAL DE ÁGUAS, 2017). Para o cálculo deste índice, são selecionados, dentre vários parâmetros, os mais significativos e, a parir daí, estipula-se para cada um destes parâmetros, pesos de acordo com a sua relevância. Atualmente, outros estados brasileiros já adotam o IQA, que hoje é o principal índice de qualidade da água utilizado no país para avaliar a qualidade da água bruta visando seu uso para o abastecimento público, após tratamento (AGÊNCIA NACIONAL DE ÁGUAS, 2017).

A NSF definiu um conjunto composto por nove parâmetros que foram considerados os mais representativos para a classificação da qualidade das águas, sendo eles: oxigênio 
dissolvido, $\mathrm{pH}$, demanda bioquímica de oxigênio, nitratos, fosfato total, turbidez, temperatura da água, sólidos totais dissolvidos e coliformes termotolerantes. Cada uma destas variáveis recebe um peso relativo, entre 0 e 1, proporcional à sua significância. Após definidos os parâmetros integrantes do IQA e os respectivos pesos, é traçada uma curva de qualidade, que correlaciona sua concentração a uma nota $q$, pontuada de zero (a pior nota) a 100 (melhor nota) (NATIONAL SANITATION FOUNDATION, 2016).

Diversas metodologias já foram desenvolvidas com o intuito de calcular o IQA com o uso de médias aritméticas e geométricas. Entretanto, deve-se ter o cuidado ao agregar inúmeras variáveis em um único número uma vez que se pode gerar uma atenuação negativa de uma das variáveis frente às demais consideradas para o cálculo (SIMÕES et al. 2007).

O IQA sugerido pela Agência Nacional de Águas (ANA) utiliza os nove parâmetros já citados acima Tais parâmetros apresentam pesos característicos $\left(w_{\mathrm{i}}\right)$, que foram fixados em função da sua importância para a conformação global da qualidade da água, conforme o Quadro 1 abaixo.

Quadro 1 - Valores de pesos de cada parâmetro do IQA

\begin{tabular}{|l|l|}
\hline Parâmetro & Peso $\left(w_{\mathbf{i}}\right)$ \\
\hline $\mathrm{OD}$ & 0,17 \\
\hline $\mathrm{CF}$ & 0,15 \\
\hline $\mathrm{pH}$ & 0,12 \\
\hline $\mathrm{DBO}_{5}$ & 0,10 \\
\hline Nitrogênio total & 0,10 \\
\hline Fosfato total & 0,10 \\
\hline Temperatura & 0,10 \\
\hline Turbidez & 0,08 \\
\hline Sólidos totais & 0,08 \\
\hline
\end{tabular}

Fonte: AGÊNCIA NACIONAL DE ÁGUAS (2017).

O IQA é calculado pelo produto ponderado da qualidade da água correspondente aos parâmetros conforme a fórmula (AGÊNCIA NACIONAL DE ÁGUAS 2017):

$\mathrm{IQA}=\prod_{i=1}^{n} q_{i}^{w_{i}}$

Onde:

IQA: Índice de Qualidade da Água (varia de 0 a 100); 
$\boldsymbol{q}_{i}$ : qualidade do i-ésimo parâmetro, um número entre 0 e 100, obtido da respectiva curva média de variação de qualidade específica para cada parâmetro, em função da sua concentração ou medida;

$w_{i}$ : peso correspondente ao i-ésimo parâmetro ou subnível, um número entre 0 e 1 (QUADRO 1), atribuído em função de sua importância para a conformação global de qualidade, sendo que:

$\boldsymbol{n}$ : número de parâmetros $(n=9)$.

A categoria é avaliada através dos parâmetros físicos, químicos e microbiológicos da qualidade da água estabelecida conforme os valores de ponderação. $\mathrm{O}$ resultado enquadra-se em uma categoria, podendo ser de ótima a péssima, conforme o Quadro 2.

Quadro 2 - Classificação do IQA - CETESB

\begin{tabular}{|l|l|}
\hline CATEGORIA & PONDERAÇÃO \\
\hline ÓTIMA & $80-100$ \\
\hline BOA & $52-79$ \\
\hline REGULAR & $37-51$ \\
\hline RUIM & $20-36$ \\
\hline PÉSSIMA & $0-19$ \\
\hline
\end{tabular}

Fonte: Agência Nacional de Águas (2017).

\section{PARÂMETROS DA QUALIDADE DA ÁGUA}

Os parâmetros utilizados no cálculo do IQA são em sua maioria indicadores de contaminação causada pelo lançamento de esgotos domésticos (AGÊNCIA NACIONAL DE ÁGUAS, 2017), e serão discutidos a seguir.

\subsection{Temperatura}

A temperatura possui duas origens quando relacionada como parâmetro de caracterização das águas. A primeira é a origem natural, e está relacionada à transferência de calor por radiação, condução e convecção entre a atmosfera e o solo, enquanto a origem antropogênica está relacionada com águas de torres de resfriamento e despejos industriais (ALVES, 2008). Sua importância como parâmetro de qualidade da água é que as elevações de temperatura aumentam as taxas das reações químicas e biológicas, diminuem a solubilidade dos gases e aumentam a taxa de transferência dos mesmos, o que pode gerar mau cheiro no caso da liberação de gases com odores desagradáveis (VON SPERLING, 2005). 


\subsection{Potencial Hidrogeniônico (pH)}

$\mathrm{O} \mathrm{pH}$ é um dos indicativos mais importantes de monitoramento de recursos hídricos superficiais ou subterrâneos. A acidez exagerada pode ser um indicativo de contaminações, enquanto o excesso de solubilização de sais também pode tornar a água imprópria para consumo devido à elevada dureza (BAIRD, 2011).

\subsection{Oxigênio Dissolvido (OD)}

O OD é de essencial importância para os organismos aeróbios. Durante a estabilização da matéria orgânica, as bactérias fazem uso do oxigênio nos seus processos respiratórios, podendo vir a causar uma redução da sua concentração no meio. Dependendo da magnitude deste fenômeno, podem vir a morrer diversos seres aquáticos, inclusive os peixes. Caso o oxigênio seja consumido, têm-se as condições anaeróbias (ausência de oxigênio), com geração de maus odores (VON SPERLING, 1996).

O teor de OD é um indicador das condições de poluição por matéria orgânica. Portanto, uma água não poluída deve estar saturada de oxigênio. Por outro lado, teores baixos de OD podem indicar que houve uma intensa atividade bacteriana decompondo matéria orgânica lançada na água (MOTA, 2012).

\subsection{Nitrogênio Total (NT)}

O nitrogênio é um constituinte de proteínas, clorofila e vários outros compostos biológicos. As fontes de contaminação desse composto em corpos d'água são de origem natural ou antropogênica, sendo a última a mais importante, pois é constituída por despejos domésticos e industriais, excrementos de animais e fertilizantes (VON SPERLING, 2005). O principal problema relacionado com altas concentrações de nitrogênio é a eutrofização. Por ser um elemento indispensável para o crescimento de algas e, estando em elevadas concentrações em lagos e represas, pode conduzir a um crescimento exagerado desses organismos, causando interferências aos usos desejáveis do corpo d'água, gerando problemas como gosto e odor, redução de oxigênio e transparência, declínio da pesca, mortandade de peixes, obstrução de cursos d'água e efeitos tóxicos sobre animais e seres humanos (VON SPERLING, 2005).

\subsection{Fósforo Total (PT)}

O fósforo é um nutriente essencial para todas as formas de vida. Ele aparece em águas naturais devido, principalmente, às descargas de esgotos sanitários. Nestes, os detergentes constituem a principal fonte, além da própria matéria fecal, que é rica em 
proteínas. As águas drenadas em áreas agrícolas e urbanas também podem provocar a presença excessiva de fósforo em águas naturais (IAP, 2005).

\subsection{Coliformes Fecais (CF)}

As bactérias do grupo coliforme constituem o indicador de contaminação fecal mais comum, sendo aplicada como parâmetro bacteriológico básico na caracterização e na avaliação da qualidade das águas em geral (VON SPERLING, 1996). As bactérias coliformes termotolerantes ocorrem no trato intestinal de animais de sangue quente e são indicadoras de poluição por esgotos domésticos. Elas não são patogênicas, mas sua presença em grande número indica a possibilidade da existência de microrganismos patogênicos que são responsáveis pela transmissão de doenças de veiculação hídrica como, por exemplo, desinteria bacilar, febre tifoide e cólera (AGÊNCIA NACIONAL DE ÁGUAS, 2017).

\subsection{Sólidos Dissolvidos Totais (SDT)}

Os sólidos podem ser classificados de acordo com o seu tamanho, as suas características químicas e a sua decantabilidade: sólidos em suspensão, sólidos dissolvidos, sólidos voláteis, sólidos fixos, sólidos em suspensões sedimentáveis e sólidos em suspensão não sedimentáveis. Os constituintes dissolvidos representam sólidos em solução verdadeira e constituem a salinidade total das águas (VON SPERLING, 2005). Em linhas gerais, as operações de secagem, calcinação e filtração são as que definem as diversas frações de sólidos presentes na água. A água com demasiado teor de sólidos dissolvidos totais não são convenientes para o uso, qualquer que seja. Quando contém menos de $500 \mathrm{mg} / \mathrm{L}$ é considerada satisfatória para o uso doméstico e para muitos fins industriais. Já acima de $1000 \mathrm{mg} / \mathrm{L}$ contém minerais que lhe conferem um sabor desagradável e a torna inadequada para diversos usos (CARVALHO, OLIVEIRA, 2003).

\subsection{Demanda Bioquímica de Oxigênio (DBO)}

A expressão DBO representa a quantidade de oxigênio molecular necessário à estabilização da matéria orgânica decomposta aerobicamente por via biológica (MOTA, 2012). Esse parâmetro é utilizado para exprimir o valor da poluição produzida por matéria orgânica, que corresponde à quantidade de oxigênio que é consumida pelos microrganismos do esgoto ou águas poluídas, na oxidação biológica, quando mantidos a uma dada temperatura por um espaço de tempo convencionado. Essa demanda pode ser suficientemente grande para consumir todo o oxigênio dissolvido da água, o que condiciona à morte de todos os organismos aeróbios de respiração subaquática. A morte 
de peixes em rios poluídos se deve, também, à ausência de oxigênio e não somente à presença de substâncias tóxicas (VON SPERLING, 1996).

\subsection{Turbidez}

A turbidez representa o grau de interferência da passagem de luz através da água, conferindo uma aparência turva à mesma. A erosão das margens dos rios em estações chuvosas é um exemplo de fenômeno que resulta no aumento da turbidez das águas. Os esgotos sanitários e diversos efluentes industriais também provocam elevações na turbidez das águas (IAP, 2005).

A turbidez é uma característica da água devido à presença de partículas suspensas com tamanho variando desde suspensões grosseiras aos coloides, dependendo do grau de turbidez. Pode ser causada por detritos orgânicos, algas, bactérias e plâncton em geral A presença dessas partículas provoca a dispersão e a absorção da luz, dando à água uma aparência nebulosa, esteticamente indesejável e potencialmente perigosa (RICHTTER; AZEVEDO NETTO, 2002). Alta turbidez reduz a fotossíntese de vegetação enraizada submersa e algas. Esse desenvolvimento reduzido de plantas pode, por sua vez, suprimir a produtividade de peixes. Logo, a turbidez pode influenciar nas comunidades biológicas aquáticas. Além disso, afeta adversamente seus usos doméstico, industrial e recreacional (COMPANHIA DE TECNOLOGIA DE SANEAMENTO AMBIENTAL, 2009).

\section{ESTUDOS SOBRE QUALIDADE DA ÁGUA REALIZADOS EM BACIAS HIDROGRÁFICAS BRASILEIRAS}

Estudos sobre a qualidade da água já foram realizados em várias bacias hidrográficas brasileiras. Garcia (2013) avaliou a qualidade da água do Rio Paraíba do Sul na cidade de Lorena - SP. Neste estudo, os parâmetros $\mathrm{pH}$, temperatura, OD, $\mathrm{DBO}, \mathrm{DQO}$ e concentração de metais pesados foram investigados. De acordo com as análises realizadas na água do rio Paraíba do Sul, os parâmetros de $\mathrm{pH}, \mathrm{DBO}$, $\mathrm{DQO}$, temperatura e concentração de metais pesados apresentaram-se dentro dos limites estabelecidos pela Resolução CONAMA no 357/2005, enquanto que os níveis de concentração de OD apresentaram-se abaixo do limite estabelecido pela Resolução CONAMA no 357/2005 em 40\% dos dias analisados. Um estudo completo dos resultados de todos os parâmetros mostra que a qualidade do rio, mesmo comprometida, ainda se encontra em condições de ser recuperada. Para isso, torna-se essencial a continuidade do monitoramento da qualidade da água e sua proteção.

Rabelo, Neto e Freire (2015) avaliaram a qualidade das águas dos córregos urbanos de Presidente Prudente - SP, com o objetivo de investigar a influência da urbanização nas águas da Bacia Hidrográfica Paraná. As concentrações dos parâmetros foram comparadas com os padrões estabelecidos pelas Resolução CONAMA no 357/2005 e 
430/2011. A situação mais crítica foi encontrada para os parâmetros coliformes fecais e também para o fósforo, sobretudo no ponto próximo aos frigoríficos e curtume, havendo a necessidade de investimentos no tratamento de efluentes e de medidas para reduzir a poluição pontual e difusa.

Guimarães (2014) avaliou, através de técnicas multivariadas, os parâmetros $\mathrm{pH}$, temperatura, condutividade, SDT, OD, turbidez e potencial redox das águas da bacia do alto Gurguéia e sub-bacia do rio Contrato, Piauí. Os parâmetros $\mathrm{pH}$, condutividade, SDT e fosfato inorgânico dissolvido não apresentaram diferenças significativas. A análise de componentes principais (PCA) promoveu a redução das variáveis originais em 3 componentes principais, explicando $71,72 \%$ da variância total dos dados, sugerindo que a sazonalidade climática e a degradação do solo a partir do município de Gilbués tiveram influência direta nos resultados. $\mathrm{O}$ mesmo também ficou evidenciado na análise de agrupamento hierárquico.

Medeiros et al. (2016) analisaram o IQA e balneabilidade no Riacho da Bica, Portalegre - RN, em três pontos e fizeram uma análise da balneabilidade na Cachoeira do Pinga, frequentemente usada por banhistas. Os resultados mostraram que a qualidade das águas é melhor na nascente do Riacho da Bica, em que o IQA foi classificado como "regular". Os demais pontos do Riacho foram classificados como "ruim". A balneabilidade das águas da Cachoeira do Pinga foi classificada como excelente.

Medeiros, Lima e Guimarães (2016) avaliaram a qualidade da água de consumo por comunidades ribeirinhas em áreas de exposição a poluentes urbanos e industriais nos municípios de Abaetetuba e Barcarena no estado do Pará. O objetivo deste estudo foi avaliar a qualidade das águas consumidas em duas comunidades ribeirinhas no Estado do Pará expostas a poluentes domésticos e industriais. Foram realizadas quatro campanhas de amostragem nas duas comunidades e as variáveis utilizadas para o cálculo do IQA foram $\mathrm{pH}$, sólidos totais, cloreto, fluoreto, dureza e nitrato. As águas utilizadas para o consumo humano na Comunidade Maranhão, onde não há contaminação por poluentes industriais, apresentaram amostras adequadas, com melhora no período seco; já as águas de Vila do Conde, local próximo à atividade industrial, estiveram em ambos os períodos sazonais com qualidade inaceitável para o consumo humano. Os principais parâmetros afetados foram o $\mathrm{pH}$ e o nitrato, com valores até 25 vezes acima no que tange à legislação brasileira para água de consumo humano. Esses resultados indicaram maior interferência antrópica no entorno da Vila do Conde em Barcarena, necessitando-se de avaliações clínicas por profissionais especializados sobre o estado de saúde desta população.

Pinto et al. (2009) estudaram a qualidade da água do Ribeirão Lavrinha, na região Alto Rio Grande - MG, com objetivo de estudar o comportamento da qualidade da água, ao longo do tempo, em uma bacia hidrográfica de cabeceira do Rio Grande. Os parâmetros analisados foram $\mathrm{pH}, \mathrm{OD}$, condutividade, salinidade, temperatura, DBO, DQO, nitrato $\left(\mathrm{NO}_{3}^{-}\right)$, nitrogênio amoniacal $\left(\mathrm{NH}_{3}\right)$, fosfato $\left(\mathrm{PO}_{4}^{3-}\right)$, turbidez, sólidos totais, STD, coliformes termotolerantes (Escherichia coli) e coliformes totais. 
Para os dados calculou-se o IQA proposto pelo Instituto Mineiro de Gestão das Águas (IGAM) e fez-se o enquadramento em classes conforme Resolução CONAMA no 357/2005. As condições ambientais refletiram-se tanto nos valores do IQA quanto no processo de enquadramento. Constatou-se ainda que o principal fator causador do quadro crítico é a quantidade de coliformes, a qual foi associada com a pecuária. Em menor escala o OD e a DBO são também fatores limitantes.

Carvalho, Ferreira e Stapelfeldt (2004) determinaram a qualidade das águas do ribeirão Ubá - MG com o IQA com base em parâmetros químicos e biológicos para determinar a qualidade da água do ribeirão. Constatou-se que, a partir da entrada da cidade, bem como à montante desta, a água do ribeirão Ubá é de má qualidade, sofrendo tanto a poluição por esgotos domésticos quanto por efluentes industriais;

Leite e Carvalho (2013) estudaram o mapa de uso e cobertura da terra na bacia hidrográfica do Ribeirão São João - TO a partir da técnica de fusão de imagens e classificação híbrida de imagens. Nos resultados encontrados, verificou-se uma evolução da malha urbana, a implantação de pastagens e a criação de reservatórios de água para diversos fins, ocasionando a supressão e a fragmentação da vegetação. A aplicação de imagens de satélites fusionadas na determinação do uso e cobertura da terra oferece exatidão às análises por apresentarem alta resolução espacial. As imagens de menor resolução espacial, no caso dos satélites Landsat e Ressourcesat, foram imprescindíveis na determinação da dinâmica do uso e cobertura da terra na bacia.

Avellar, Castro e Hadad (2008) utilizaram os recursos dos Sistemas de Informações Geográficas (SIG’s) para avaliar as alterações ocorridas no uso do solo da Bacia do Ribeirão São João, no período de 1990 a 2000, após ações de intervenções no ecossistema, espacializando os níveis hierárquicos de fragilidade ambiental do geoecossistema local como subsídio a programas de financiamento público em bacias hidrográficas. O resultado mostrou que a qualidade ambiental da área compreendida pela Bacia do Ribeirão São João tem um equilíbrio que, para ser mantido, deve continuar a atender às recomendações de recuperação já iniciadas. As mudanças ocorridas no âmbito da Bacia do Ribeirão São João refletem as políticas vigentes de uso desordenado do solo. No que refere às normas de qualidade da água, a presença de metais pesados e efluentes sanitários coloca em risco a saúde da população e da Bacia Hidrográfica.

Moretto et al. (2012), estudando a Bacia Hidrográfica do Rio Pardo, RS, mostraram que não há concordância entre a avaliação da qualidade da água obtida através do Índice da Qualidade da Água (IQA - NSF), que oscilou entre boa e regular, e da Resolução 357/2005 do Conselho Nacional de Meio Ambiente (CONAMA), que foi ruim (classe 4), destacando como variáveis críticas para esta classificação os coliformes termotolerantes e a concentração de fosfato. O objetivo do estudo foi calibrar o IQA - NSF para a Bacia Hidrográfica do Rio Pardo, baseando-se na Resolução 357/2005 do CONAMA. Usando o banco de dados (2007 a 2009) novos pesos da importância relativa das variáveis usadas para calcular o IQA foram atribuídos, por meio de análise de componentes principais, havendo uma significativa concordância 
entre os resultados da avaliação da qualidade da água utilizando a Resolução 357/2005 do CONAMA e o novo IQA calibrado.

\section{CONCLUSÕES}

O IQA apresenta-se como uma importante ferramenta para a avaliação da qualidade de águas. Porém, cabe ressaltar que este índice deve ser adotado como uma complementação às informações geradas por cada parâmetro avaliado em consonância com os padrões de qualidade determinados pelas legislações específicas. Assim, o IQA tem um importante papel para averiguar eventuais deteriorações dos recursos hídricos ao longo de bacias hidrográficas.

\section{REFERENCIAS}

AGÊNCIA NACIONAL DE ÁGUAS - ANA. Indicadores de qualidade - Índice de qualidade das águas (IQA). Disponível em: <http://portalpnqa.ana.gov.br/indicadores-indiceaguas.aspx>. Acesso em: 27 mai. 2017.

ALVES, Eliane C. et al. Avaliação da qualidade da água da bacia do rio Pirapó - Maringá, Estado do Paraná, por meio de parâmetros físicos, químicos e microbiológicos. Acta

Scientiarum. Technology, v. 30, n. 1, p. 39-48, 2008.

AVELLAR, Gisela; CASTRO, José F. M.; HADAD, Renato M. Análise geoecossistêmica da bacia do ribeirão São João com uso de sig. Revista Climatologia e Estudos da Paisagem, v. 3, n. 1, p. 19-38, 2008.

BAIRD, Colin; CANN, Michael. Química Ambiental. 4. ed. Porto Alegre: Bookman, 2011.

BRAGA, Benedito et al. Introdução à Engenharia Ambiental. 2. ed. São Paulo: Pearson Prentice Hall, 2005.

BRASIL. Lei no 6.938, de 31 de agosto de 1981. Dispõe sobre a Política Nacional do Meio Ambiente, seus fins e mecanismos de formulação e aplicação, e dá outras providências.

Disponível em: < http://www.planalto.gov.br/ccivil_03/leis/L6938.htm>. Acesso em: 30 mai. 2017.

BRASIL. Lei n 9.433 de 08 de janeiro de 1997. Institui a Política Nacional de Recursos Hídricos, cria o Sistema Nacional de Gerenciamento de Recursos Hídricos, regulamenta o inciso XIX do art. 21 da Constituição Federal, e altera o art. $1^{\circ}$ da Lei no 8.001, de 13 de março de 1990, que modificou a Lei no 7.990, de 28 de dezembro de 1989. Disponível em: <http://www.planalto.gov.br/ccivil_03/leis/L9433.htm>. Acesso em: 28 mai. 2017.

BRASIL. Resolução no 357, de 17 de março de 2005. Conselho Nacional do Meio Ambiente. Dispõe sobre a classificação dos corpos de água e diretrizes ambientais para o seu enquadramento, bem como estabelece as condições e padrões de lançamento de efluentes, 
e dá outras providências. Disponível em: <http://www.mma.gov.br/port/conama/res/res05/ res35705.pdf> Acesso em: 27 mai. 2017.

BRITO, Luiza T. L. Influência das atividades Influência das atividades antrópicas na qualidade das águas antrópicas na qualidade das águas da bacia hidrográfica do da bacia hidrográfica do Rio Salitre. Revista Brasileira de Engenharia Agrícola e Ambiental, v. 9, n. 4, p. 596-602, 2005.

BUENO, Lara F.; GALBIATTI, João A.; BORGES, Maurício J. Monitoramento de variáveis de qualidade de água no horto Ouro Verde - Conchal - SP. Ver. Engenharia Agrícola, Jaboticabal, v. 25, n. 3, p. 742-748, 2005.

CARVALHO, Cornélio F.; FERREIRA, Adalberto L.; STAPELFELDT, Frank. Qualidade das águas do ribeirão Ubá - MG. Revista Escola de Minas, Ouro Preto, v. 57, n. 3, p. 165-172, 2004.

CARVAlHO, Anésio R; OLIVEIRA, Maria C. V. Princípios básicos de saneamento do meio. 3. ed. São Paulo: Editora SENAC, 2003.

CARVALHO, Rinaldo C. Análise matemática de investimentos em processos de despoluição de bacias hidrográficas. Dissertação (Programa de Pós-Graduação em Engenharia de Recursos Hídricos e Ambientais). Universidade Federal do Paraná. 2005.

CBH - Comitês de Bacias Hidrográficas. 2017. Disponível em:< http://www.cbh.gov.br/>. Acessado em: 29 mai. 2017.

COIMBRA, R. M. Monitoramento da qualidade da Água. In: BRANCO, S. M., PORTO, R. L. L, et al. Hidrologia Ambiental. São Paulo: USP/ABRH (Coleção ABRH de recursos hídricos) v. 3,p. 392-411, 1991.

COMPANHIA DE TECNOLOGIA DE SANEAMENTO AMBIENTAL - CETESB. Qualidade das Águas Interiores no Estado de São Paulo, Significado Ambiental e Sanitário das Variáveis de Qualidade das Águas e dos Sedimentos e Metodologias Analíticas e de Amostragem. São Paulo, 2009.

DERÍSIO, José C. Introdução ao controle de poluição ambiental. 1. ed. São Paulo: CETESB, 1992.

GARCIA, A.C. Avaliação da qualidade da água do rio Paraíba do Sul na Cidade de Lorena - SP Brasil. In: 13 Congresso Nacional de Iniciação Científica, São Paulo. Anais ConicSemesp, 2013.

GUIMARÃES, G. S. C. Parâmetros físico-químicos das águas da bacia do Alto Gurguéia e sub-bacia do rio Contrato, PI. 2014. 51 f. Dissertação (mestrado) - Curso de Agronomia, Universidade Federal do Piauí, Bom Jesus, 2014.

IAP. Relatório de Monitoramento da Qualidade das águas dos rios da região de Curitiba, no período de 1992 a 2005. Curitiba, 2005. Disponível em : <http://www.iap.pr.gov.br/arquivos/ File/Monitoramento/monitoramento_da_qualidade_agua_1992_2005.pdf $>$. Acessado em 16 jun. 2016. 
JUNIOR, A. P. Saneamento, Saúde Ambiente: Fundamentos para um Desenvolvimento Sustentável. 1.ed. São Paulo: Manole, 2005.

LEITE, Emerson F. L.; CARVALHO, Elisângela M. Mapeamento do uso e cobertura da terra na bacia hidrográfica do ribeirão São João, Porto Nacional, Tocantins. Geoambiente online, n. 20, p. 97-110, 2013.

MEDEIROS, Samylle R. M. et al. Índice de qualidade das águas e balneabilidade no Riacho da Bica, Portalegre, RN, Brasil. Revista Ambiente e Água, v. 11, n. 3, p. 711-730, 2016.

MEDEIROS, Adaelson C.; LIMA, Marcelo O. ; GUIMARAES, Raphael M. Avaliação da qualidade da água de consumo por comunidades ribeirinhas em áreas de exposição a poluentes urbanos e industriais nos municípios de Abaetetuba e Barcarena no estado do Pará, Brasil.

Ciência e Saúde Coletiva, v. 21, n. 3, p. 695-708, 2016.

MEYBEC, M.; HELMER, R. An introduction to water quality. In: CHAPMAN, D. Water Quality Assessments - A Guide to Use of Biota, Sediments and Water in Environmental Monitoring. 2nd Edition Cambridge: University Press, 1996.

MEYBECK M. The Global Change of continental aquatic systems: dominant impacts of human activities. Water Science \& Technology, v. 49, n. 7, p. 73-83, 2004.

MERTEN, G. H.; MINELLA, J. P. Qualidade da água em bacias hidrográficas rurais: um desafio atual para a sobrevivência futura. Agroecologia e Desenvolvimento Rural Sustentável. Porto Alegre, 2002.

MORETTO, Daiane L. et al. Calibração do índice de qualidade da água (IQA) com base na Resolução no 357/2005 do Conselho Nacional do Meio Ambiente (CONAMA). Acta Limnologica Brasiliensia, v. 24, n. 1, p. 29-42, 2012.

MOTA, S. Introdução à engenharia ambiental. 5. ed. Rio de Janeiro:ABES, 2012.

NATIONAL SANITATION FOUNDATION - NSF. Consumer Information: Water Quality Index (WQI). Disponível em: <http://www.nsf.org/consumer/earth_day/wqi.asp>. Acesso em: 07 mar. 2016.

PINTO, Daniel. B. et al. Qualidade da água do Ribeirão Lavrinha na região Alto Rio Grande - MG, Brasil. Revista Ciência e Agrotecnologia, v. 33, n. 4, p. 1145-1152, 2009.

RABELO, Gabriel C.; NETO, José. B.; FREIRE, Rosane. Qualidade das águas dos Córregos urbanos de Presidente Prudente: Análise preliminar. Revista Nacional de Gerenciamento de Cidades, v. 3, n. 15, p. 18-38, 2015.

RICHTTER, C. A.; AZEVEDO NETTO, José. M. Tratamento de água: tecnologia atualizada. São Paulo: Edgard Blucher, 2002.

SÁ, José A. C. A.; CAMPOS, Luciana R. O Direito e a Gestão das Águas. In: CAMPOS, Nilson; STUDART, Ticiana M. C. (Eds.) Gestão das Águas: princípios e práticas. 2. ed. Porto Alegre: ABRH, 2003. p. 216-237. 
SIMÕES, F. et al. Avaliação do efeito da piscicultura em sistemas aquáticos em Assis e Cândido Mota, São Paulo, por indicador de qualidade da água e análise estatística multivariada. Química Nova, v. 30, n. 8, p. 1835-1841, 2007.

TEIXEIRA, D. Avaliação da qualidade da água e levantamento de custo de tratamento de efluentes visando a recuperação de um sistema eutrofizado (Represa de Salto Grande - Americana/SP). 2000. 186 f. Tese (Doutorado) Curso Pós Graduação em Ciências da Engenharia Ambiental, Universidade de São Paulo, São Carlos, 2000.

TUCCI, C. E. M., Hidrologia: ciência e Aplicação. 4. ed. Porto Alegre: Editora da UFRGS/ ABRH, 2007.

VON SPERLING, M. Introdução à qualidade das águas e ao tratamento de esgotos. 2. ed. Belo Horizonte: Editora UFMG, 1996.

VON SPERLING, M. Princípios do tratamento biológico das águas residuárias. 3. ed. Belo Horizonte: Editora UFMG, 2005. 